Check for updates

Cite this: RSC Adv., 2019, 9, 4361

Received 30th November 2018 Accepted 21st January 2019

DOI: $10.1039 / \mathrm{c} 8 \mathrm{ra0} 0955 \mathrm{~g}$

rsc.li/rsc-advances

\section{Preparation and characterization of a novel positively charged composite hollow fiber nanofiltration membrane based on chitosan lactate $\uparrow$}

\author{
Yuantao He, ab Jing Miao, iD *ac Shunquan Chen, ${ }^{a}$ Rui Zhang, ${ }^{\text {cc }}$ Ling Zhang, (DD *d \\ Haolin Tang (iD *e and Hao Yang (D) *b
}

A positively charged composite hollow fiber nanofiltration (NF) membrane was prepared via interfacial polymerization (IP) between chitosan lactate $(C L)$ and trimesoyl chloride (TMC) on a polyether sulfone (PES) hollow fiber ultrafiltration (UF) membrane. The chemical structure and the morphologies of the resultant NF membranes were characterized with attenuated total reflectance-infrared spectroscopy (ATR-IR) and scanning electron microscopy (SEM). The rejection of NF membrane for different inorganic salt aqueous solutions followed the order: $\mathrm{MgCl}_{2}>\mathrm{ZnCl}_{2}>\mathrm{MgSO}_{4}>\mathrm{NaCl}>\mathrm{Na}_{2} \mathrm{SO}_{4}$. It suggested that this novel kind of composite hollow fiber NF membrane is positively charged. The molecular weight cutoff (MWCO) was obtained through the rejection of polyethylene glycol (PEG) solutions with different molecular weights $\left(M_{w}\right)$. The effect of monomer concentrations, the interfacial polymerization time, and the curing temperature, were investigated, respectively. The rejection and the permeate flux of the resultant composite hollow fiber $\mathrm{CL}$ membrane fabricated under the optimal conditions towards a $\mathrm{MgCl}_{2}$ solution of $1000 \mathrm{ppm}$ were $95.1 \%$ and $10.3 \mathrm{~L} \mathrm{~m}^{-2} \mathrm{~h}^{-1}$, respectively, at $0.4 \mathrm{MPa}$ and $25^{\circ} \mathrm{C}$. Moreover, the effects of operation conditions on the rejection performance of the composite hollow fiber NF membrane were investigated. It suggested that this novel kind of hollow fiber composite nanofiltration membrane based on CL have excellent stability in rejection performances to salt solutions.

\section{Introduction}

Currently, nanofiltration (NF) is drawing more and more attention due to its advantages such as lower operation pressure, lower energy consumption, and excellent separation performance of multi/di-valent ions and low-molecular-weight (LWM) organic compounds from 200 to $1000 \mathrm{Da}^{1-3}$ The NF membrane is a kind of pressure-driven membrane, whose mechanisms of rejecting ions and LMW organic compounds are

${ }^{a}$ Guangdong Key Laboratory of Membrane Materials and Membrane Separation, Guangzhou Institute of Advanced Technology, Chinese Academy of Sciences, Nansha District, Guangzhou, 511458, China. E-mail: jing.miao@giat.ac.cn; jmiao@ jinzhenghb.com; Fax: +86-2022912525; Tel: +86-13829708450

${ }^{b}$ Key Laboratory for Green Chemical Process of Ministry of Education, School of Chemical Engineering and Pharmacy, Wuhan Institute of Technology, Wuhan, 430205, China. E-mail: hyang@wit.edu.cn

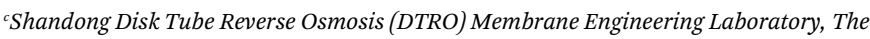
New Water Technology, Inc. (NEWA), China. E-mail: niureal@gmail.com

${ }^{d}$ School of Resource and Environment, University of Jinan, Jinan 250022, China. E-mail: chm_zhangl@ujn.edu.cn

${ }^{e}$ State Key Laboratory of Advanced Technology for Materials Synthesis and Processing, Wuhan University of Technology, Wuhan 430070, China. E-mail: thln@whut.edu.cn $\dagger$ Electronic supplementary information (ESI) available. See DOI: $10.1039 / \mathrm{c} 8 \mathrm{ra09855g}$ based on a sieving effect and Donnan exclusion., ${ }^{4,5} \mathrm{NF}$ membranes have been widely used in seawater desalination, ${ }^{6}$ industrial wastewater treatment, ${ }^{7}$ drinking water purification, ${ }^{8}$ biotechnology ${ }^{9}$ and food science. ${ }^{10}$ According to previous studies, positively-charged NF membranes show better performance in some specific fields, such as recovery of high-valence metal ions, ${ }^{11}$ separation of positively charged amino acids and proteins, ${ }^{12}$ and so on. However, most of the current commercial NF membranes on the market are negatively charged. ${ }^{\mathbf{1 3 , 1 4}}$ Thus it is meaningful to develop and industrialize some novel kinds of positively charged NF membranes.

Various methods have been applied to prepare positively charged NF membranes, such as interfacial polymerization, phase inversion method, chemical cross-linking, UV-induced photografting, etc. ${ }^{15-18}$ Wei et al. ${ }^{19}$ developed a positively charged NF membrane via interfacial polymerization by using polyethyleneimine (PEI) and trimesoyl chloride (TMC). The zeta potentials results indicated that the surface of the resultant PEI composite NF membrane was positively charged as $\mathrm{pH}$ is being below 8.2. The resultant NF membrane shows good rejection $(R)$ to metal ions, 92.6, 89.6, 89.2 and $86.3 \%$, to chromium, nickel, zinc and copper ions, respectively. Mahendran, et al. ${ }^{20}$ prepared a positively charged NF membrane from aminated polysulfone 
(APSF) via a two-step phase inversion method, the resultant membrane showed the highest rejection $(R)$ of $99.5 \%$ to $500 \mathrm{ppm} \mathrm{CrCl}_{3}$ solution. Cui, et al. ${ }^{21}$ fabricated another novel kind of positively charged NF membrane by utilizing quaternization and cross-linking reaction between $p$-xylylene dichloride (XDC) and tertiary amine units in PVC/PMMA-co-DMA precursor membranes. The resultant membrane exhibited $89.1 \%$ rejection to $2000 \mathrm{ppm} \mathrm{MgCl}_{2}$ solution. $\mathrm{Mu}$, et al. ${ }^{22}$ fabricated a positively charged NF membrane with a rejection of $95.7 \%$ for $\mathrm{CaCl}_{2}$ solution by grafting chiral mesogenic compound and charged compound to chitosan.

Most of these studies were concentrated on preparation and characterization of flat-sheet composite NF membranes. Compared to the flat-sheet membranes, hollow fiber membranes have some advantages such as higher packing density, higher specific surface area, and self-supporting capability. ${ }^{23-25}$

Chitin was an abundant natural resource, just second to cellulose on the earth. Chitosan is the deacelation product of chitin with excellent film/membrane-forming characteristic. ${ }^{26-28}$ Tang, et $a .^{29}$ developed a chitosan (CS)-piperazine (PIP) composite NF membrane through IP on the polysulfone (PSF) UF membrane. The CS-PIP NF membrane reached a permeate flux $(F)$ of $67.4 \mathrm{~L} \mathrm{~m}^{-2} \mathrm{~h}^{-1}$ and a rejection rate $(R)$ of $90.3 \%$ for $\mathrm{Na}_{2} \mathrm{SO}_{4}$ at $0.6 \mathrm{MPa}$ and $20{ }^{\circ} \mathrm{C}$, respectively. Ghaee, et al. ${ }^{30}$ developed a chitosan/cellulose acetate (CA) blend composite NF membrane via chemical cross-linking. The CS/CA composite membrane had $81.0 \%$ retention for copper ions. The MWCO of the resultant membrane was $830.7 \mathrm{Da}$, and the mean pore size was $0.78 \mathrm{~nm}$. On the other hand, there are numerous amino and hydroxyl groups on chitosan molecular chains, so chitosan is chemically active and could be modified easily. ${ }^{31,32}$ The anionic, cationic, and amphoteric derivatives of chitosan could be obtained through different chemical modifications. Chitosan lactate (CL) is a ramification derivative of chitosan. CL could be obtained via the following details: dissolving chitosan in lactate acid, and following filtration, freezing, desiccation. It retains the good membrane-forming property and has excellent water solubility as well. ${ }^{33,34}$ Fig. 1(a) shows the molecular structure of CL.

In this work, a positively-charged nanofiltration membrane was developed via interfacial polymerization by using chitosan lactate and trimesoyl chloride (TMC) as the aqueous phase solute and the organic phase solute, respectively. Fig. 1(b) shows the molecular structure of TMC. The interfacial polymerization occurred between the residual amine $\left(-\mathrm{NH}_{2}\right)$ and the acyl chloride groups $(-\mathrm{COCl})$ on the top of polyether sulfone (PES) hollow fiber ultrafiltration (UF) membrane (Scheme 1). The chemical structure and morphology were characterized with attenuated total reflectance-infrared spectrossch1copy (ATR-IR) and scanning electron microscopy (SEM). The rejection reached maximum $95.1 \%$ for $2000 \mathrm{ppm} \mathrm{MgCl}_{2}$ solution as the IP time was $120 \mathrm{~s}$. CL/PES composite hollow fiber NF membranes showed good retentions of heavy metal ions, and the rejection of the nanofiltration membrane for inorganic salts followed in an order of: $\mathrm{ZnCl}_{2}>\mathrm{MgCl}_{2}>\mathrm{MgSO}{ }_{4}>\mathrm{NaCl}>$ $\mathrm{Na}_{2} \mathrm{SO}_{4}$, showing the typical rejection characteristic of positively charged NF membrane to different inorganic salts. This work will provide the base for the scale-up and the industrialization of CL composite NF membranes.

\section{Materials and methods}

\subsection{Materials}

Polyether sulfone (PES) hollow fiber ultrafiltration (UF) membranes with MWCO of $50 \mathrm{kDa}$ were self-made in lab. The pure water permeate flux at 0.1 MPa of PES hollow fiber UF membrane is $53 \mathrm{~L} \mathrm{~m}^{-2} \mathrm{~h}^{-1}$. Chitosan lactate (CL, $\left.M_{\mathrm{w}} \sim 30 \mathrm{kDa}\right)$ with the solubility of $65 \mathrm{~g} \mathrm{~L}^{-1}$ was purchased from Wuhan

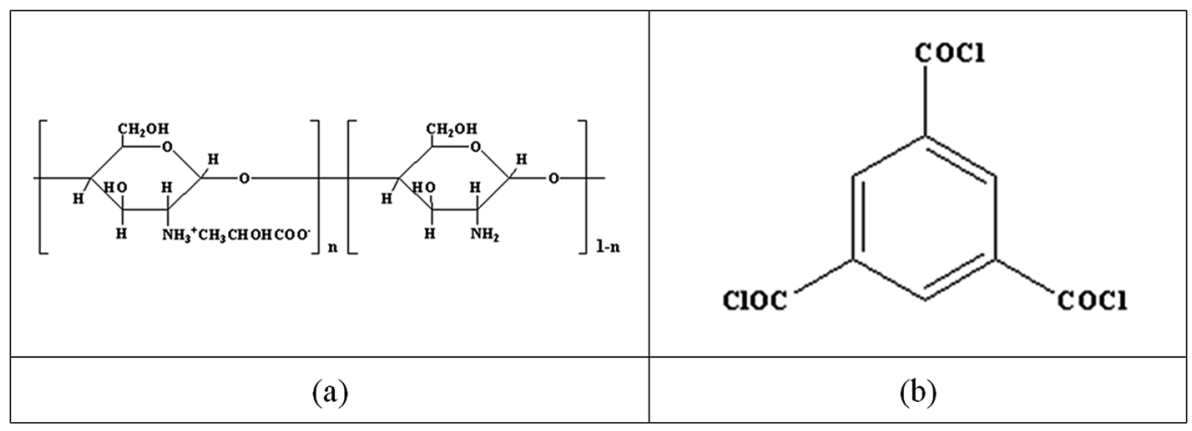

Fig. 1 The molecular structures of (a) CL, and (b) TMC.
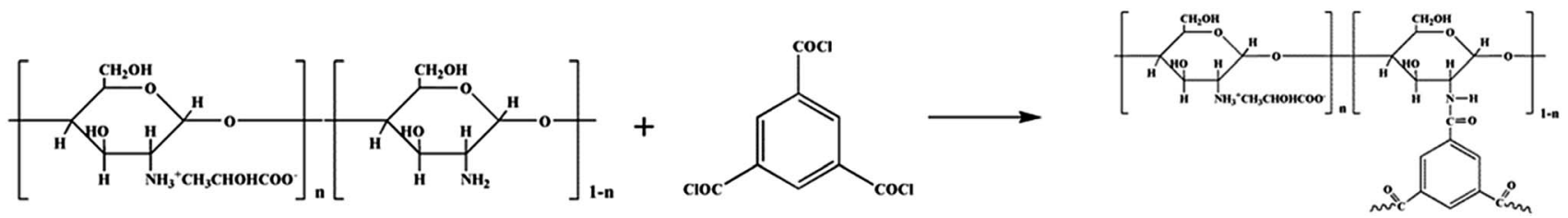

Scheme 1 Interfacial polymerization between $\mathrm{CL}$ and TMC. 
Yuancheng Gongchuang Technology Co. Ltd (Wuhan, China). PEG with different $M_{\mathrm{w}}$ in the range of 200 to $1000 \mathrm{Da}$ and trimesoyl chloride (TMC, 98\%) was obtained from Shanghai Macklin Biochemical Co. Ltd (Shanghai, China). Inorganic salts, including magnesium chloride $\left(\mathrm{MgCl}_{2}, \mathrm{AR}\right)$, sodium sulfate $\left(\mathrm{Na}_{2} \mathrm{SO}_{4}, \mathrm{AR}\right)$, magnesium sulfate $\left(\mathrm{MgSO}_{4}, \mathrm{AR}\right)$, sodium chloride ( $\mathrm{NaCl}, \mathrm{AR})$, were obtained from Sinopharm Chemical Reagent Co. Ltd (Shanghai, China). All reagents are of analytical grade and there was no further purification.

\subsection{Fabrication of PES hollow fiber membrane}

The PES hollow fiber membranes were prepared by phaseinversion method. The casting solution contains $16 \mathrm{wt} \%$ PES, 10 wt\% PVP, 10 wt\% PEG400 and 74 wt\% DMAc. The casting solution was degassed for $6 \mathrm{~h}$ in the pump prior to spinning. Subsequently, the casting solution was pumped into a spinneret with the outer diameter of $1.2 \mathrm{~mm}$. After that, the nascent fibers were formed in a coagulation tank after passing through a certain air gap, and then the fibers were collected by a take-up unit. As shown in Fig. S1, $\uparrow$ the structure morphology of the hollow fiber membrane was measured by SEM. The parameters of PES hollow fiber membrane were showed in Table S1.†

\subsection{Preparation of composite hollow fiber CL/PES NF membranes}

After being pre-soaked for $24 \mathrm{~h}$ in deionized (DI) water for removing contaminants, the two ends of the hollow fiber membrane were sealed with a sealant to prevent the monomer solution from entering the lumen side of the hollow fiber. The PES UF membranes were immersed in the CL aqueous solution for $5 \mathrm{~min}$ and then poured out, and the excess CL aqueous solution was removed at ambient temperature in air by blowing. Next, these membranes were immersed in TMC in $n$-hexane for $120 \mathrm{~s}$ and then poured out. After removing the excess TMC solution by blowing, the membranes were cured for $20 \mathrm{~min}$ in an oven at $90{ }^{\circ} \mathrm{C}$. Finally, the resultant composite hollow fiber CL/PES NF membranes were washed extensively, and sealed in a PMMA pipe to obtain the hollow-fiber membrane modules.

\subsection{Characterizations of composite hollow fiber NF membranes}

The surface and cross-section morphologies of PES UF membranes and as-prepared composite NF membranes were characterized using a scanning electron microscopy (SEM, Phenom ProX, Netherlands). The attenuated total reflectance Fourier transform infrared (ATR-IR) spectra were collected in the range of 600 to $4000 \mathrm{~cm}^{-1}$ at a resolution of $4 \mathrm{~cm}^{-1}$ with a benchtop spectrometer (Nicolet iS10, Thermo Fisher Scientific, the United States), to characterize the chemical structures of the resultant composite NF membrane surfaces. The hydrophilicities of the membrane surfaces were characterized with the static contact angle measurements (DSA305, Kruss GmbH, Germany) using $0.2 \mu \mathrm{L}$ droplet of pure water. Surface charge properties of the membranes were studied by measuring streaming potentials at various $\mathrm{pH}$ values ranging from 5 to 12 using a SurPASS electrokinetic analyzer (Anton Paar GmbH, Austria). The streaming potential was measured in a $0.001 \mathrm{~mol} \mathrm{~L}^{-1} \mathrm{KCl}$ solution at $25{ }^{\circ} \mathrm{C}$. Auto titrations with $0.1 \mathrm{M} \mathrm{HCl}$ and $0.1 \mathrm{M} \mathrm{NaOH}$ were carried out to adjust the $\mathrm{pH}$ of the electrolyte solution.

Rejection performance including permeate flux $(F)$ and rejection rate $(R)$ were measured with a lab-scale cross-flow membrane evaluation apparatus at $25{ }^{\circ} \mathrm{C}$. The texts were carried out with concentration of inorganic salt aqueous solution of $1000 \mathrm{ppm}$ at an operating pressure of $0.4 \mathrm{MPa}$. The permeation flux $(F)$ was calculated using the following equation.

$$
F=V /(S t)
$$

where, $V$ is the volume of permeated aqueous solution during the measurement, $S$ is the effective membrane area, $t$ is the time period for measurement.

The rejection rate was calculated using the following equation:

$$
R=100 \times\left(1-\left(C_{\mathrm{p}} / C_{\mathrm{f}}\right)\right)
$$

where, $C_{\mathrm{p}}$ and $C_{\mathrm{f}}\left(\mathrm{mol} \mathrm{L}^{-1}\right)$ are the salt concentration in the permeate and the feed solution. The salt concentrations were obtained by the standard curves of different salts, which show the corresponding relations between the salt concentrations and the electrical conductivities of the aqueous solutions. The electrical conductivities of the salt aqueous solutions were measured by a DDS-11A conductivity meter (Shanghai Leici Instrument Company, China). All experiment results were the average values of 5 measurements.

The MWCO was known from the permeation test of PEG with different $M_{\mathrm{w}}$ in the range of 200 to $1000 \mathrm{Da}$. The PEG concentrations in the feed and permeated solution were measured by ultraviolet (UV)-visible (Vis) spectrophotometer (UV-6100, Shanghai Mapada Instruments Co., Ltd., China).

\section{Result and discussion}

\subsection{Chemical structures of membrane surfaces}

Fig. 2 shows the ATR-IR spectra of PES substrate and asprepared CL/PES composite NF membrane. As known from Fig. 2, there is a broad absorbance peak at $3350 \mathrm{~cm}^{-1}$, corresponding to the overlap of the amine groups $(-\mathrm{N}-\mathrm{H})$ and hydroxyl groups $(-\mathrm{O}-\mathrm{H})$ stretching vibrations. A new absorbance peak occurred at $1728 \mathrm{~cm}^{-1}$, which was the characteristic peak of the carbonyl group $(-\mathrm{C}=\mathrm{O})$ in the lactic acid groups. Absorbance peak at $1650 \mathrm{~cm}^{-1}$ attributed to carbonyl group $(-\mathrm{C}=\mathrm{O})$ of the amide groups was enhanced significantly, suggesting the occurrence of the interfacial polymerization between the amine groups of CL and the acyl chloride groups of TMC. The peaks around $1578 \mathrm{~cm}^{-1}$ and $1486 \mathrm{~cm}^{-1}$ are due to the stretching vibration of $\mathrm{C}=\mathrm{C}$ skeleton in aromatic ring. A new absorbance peak presented at $1083 \mathrm{~cm}^{-1}$, which was attributed to the stretching vibration of $-\mathrm{C}-\mathrm{O}$ of the lactic acid groups.

\subsection{Membrane morphologies}

The SEM images for the surface and cross-section morphologies of the PES substrate membrane and the CL/PES composite NF 


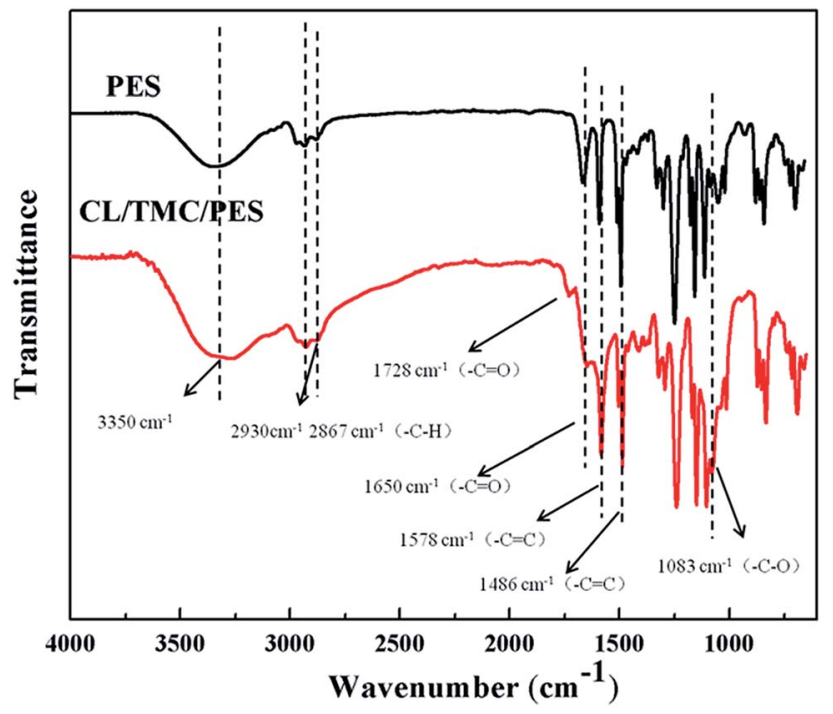

Fig. 2 ATR-FTIR spectra of PES UF membrane and the resultant CL/ PES composite NF membrane.

membrane were shown in Fig. 3. It could be observed from Fig. 3(a1) that the surface of PES hollow fiber UF membrane is porous. Fig. 3(a2) shows the cross-section image of PES UF hollow fiber UF membrane, where a typical macrovoid structure of UF membrane could be observed. Fig. 3(b1) shows the surface image of the hollow fiber composite NF membrane, in which no visible pores could be observed on the surface of the resultant $\mathrm{CL} / \mathrm{PES}$ composite NF membranes. As known from
Fig. 3(b2), the dense layer with a thickness of approximate $273 \mathrm{~nm}$ could be clearly found out on the top surface of the PES substrate membrane, suggesting that a compact polyamide layer was formed on the PES UF substrate.

\subsection{Hydrophilicities of membrane surfaces}

The static contact angles of resultant $\mathrm{CL} / \mathrm{PES}$ composite NF membrane surfaces were shown in Fig. 4. Compared with the PES UF base membrane with a water contact angle of $96.1^{\circ}$, all of the CL/PES composite NF membranes were more hydrophilic because of the formation of the hydrophilic polyamide active layer on the top of PES UF membrane. The static contact angle of the CL/PES composite NF membranes decreased from 65.1 to $26.3^{\circ}$ with increasing the CL concentration from 0.8 to $4.8 \mathrm{wt} \%$. The higher the CL concentration in the aqueous phase, the more the hydrophilic groups such as polyamide and hydroxyl groups on the membrane surface, which might be the reason for the increase in the hydrophilicity of resultant CL NF membrane surface.

\subsection{Rejection performances}

3.4.1. Rejection performances of the CL/PES composite hollow fiber NF membrane to different inorganic salt solutions. The rejection performances were evaluated with a variety of inorganic salt solutions. The CL/PES composite hollow fiber NF membranes were fabricated under the following conditions: immersion time in $3.2 \mathrm{wt} \% \mathrm{CL}$ aqueous solution: $5 \mathrm{~min}$, interfacial polymerization (IP) time: $120 \mathrm{~s}$, TMC concentration:

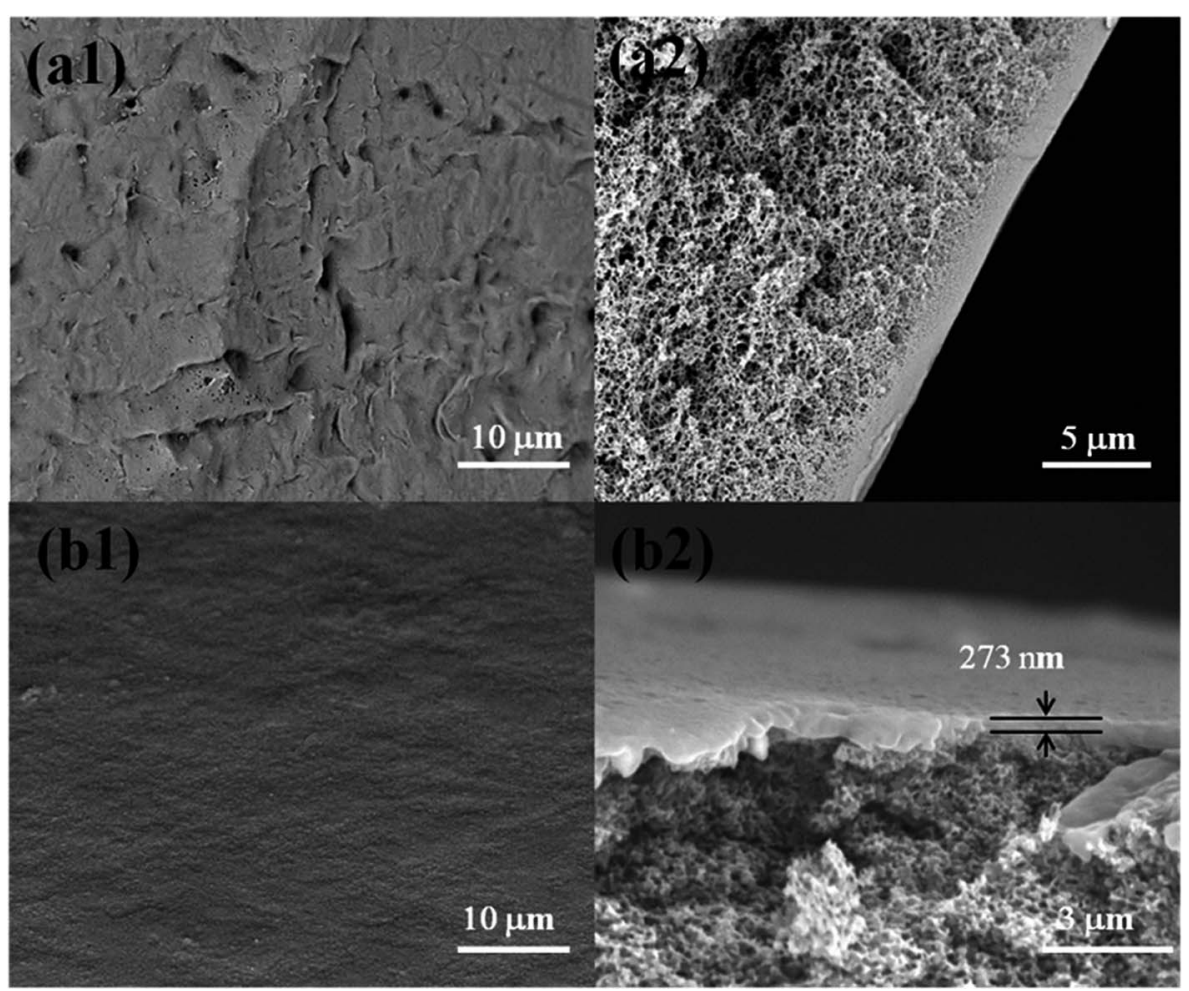

Fig. 3 SEM images of PES UF membrane ((a1) the surface, (a2) the cross section) and CL/PES composite NF membrane ((b1) the surface, (b2) the cross section). 


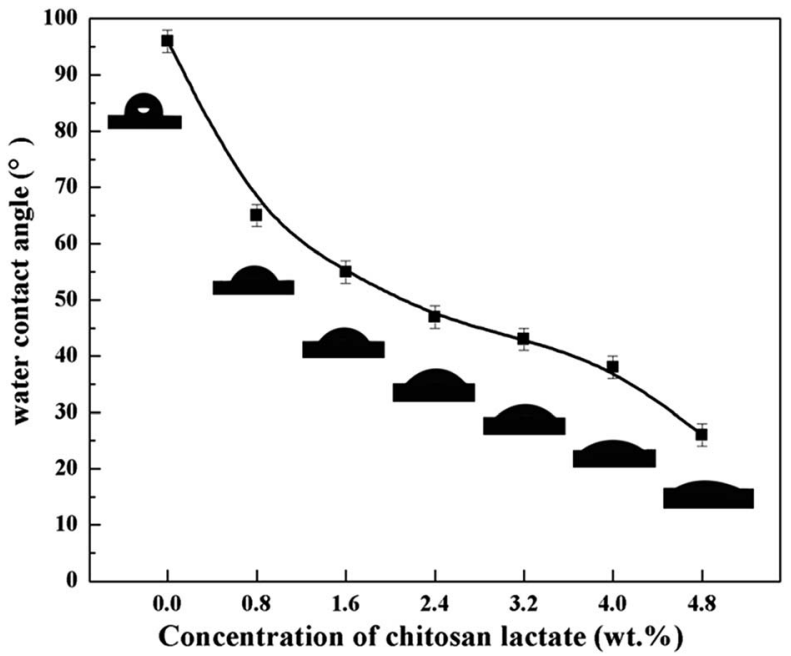

Fig. 4 Static contact angles of CL/PES composite NF membranes and PES UF membrane (CL concentration: 0 wt\%).

$0.25 \mathrm{wt} \%$, and curing temperature: $90{ }^{\circ} \mathrm{C}$. As shown in Fig. 5 , the permeate flux $(F)$ for a feed solution of $\mathrm{ZnCl}_{2}, \mathrm{MgCl}_{2}, \mathrm{MgSO}_{4}$, $\mathrm{NaCl}$ and $\mathrm{Na}_{2} \mathrm{SO}_{4}$ were 10.0, 10.3, 12.7, 14.6, and $14.2 \mathrm{~L} \mathrm{~m}^{-2} \mathrm{~h}^{-1}$, respectively. The rejections $(R)$ decreased in an order of $\mathrm{ZnCl}_{2}$ $(95.7 \%)>\mathrm{MgCl}_{2}(95.1 \%)>\mathrm{MgSO}_{4}(59.7 \%)>\mathrm{NaCl}(27.6 \%)>$ $\mathrm{Na}_{2} \mathrm{SO}_{4}(22.3 \%)$, which could be explained by Donnan exclusion theory. $\mathrm{Mg}^{2+}$ has a higher positive valence than $\mathrm{Na}^{+}$, and $\mathrm{SO}_{4}{ }^{2-}$ has a higher negative valence than $\mathrm{Cl}^{-}$. High-valence cations carrying more positive charges lead to a stronger repulsion between the cations and the positively-charged CL/PES composite NF membrane. On the contrary, high-valence anions carrying more negative charges would have a stronger attraction to CL membrane. ${ }^{35}$ The rejection of CL/PES composite $\mathrm{NF}$ membrane to $\mathrm{ZnCl}_{2}$ was higher than that to $\mathrm{MgCl}_{2}$. It could be explained by the steric hindrance because the size of $\mathrm{Zn}^{2+}$ is larger than that of $\mathrm{Mg}^{2+} \cdot{ }^{\mathbf{1 1}}$

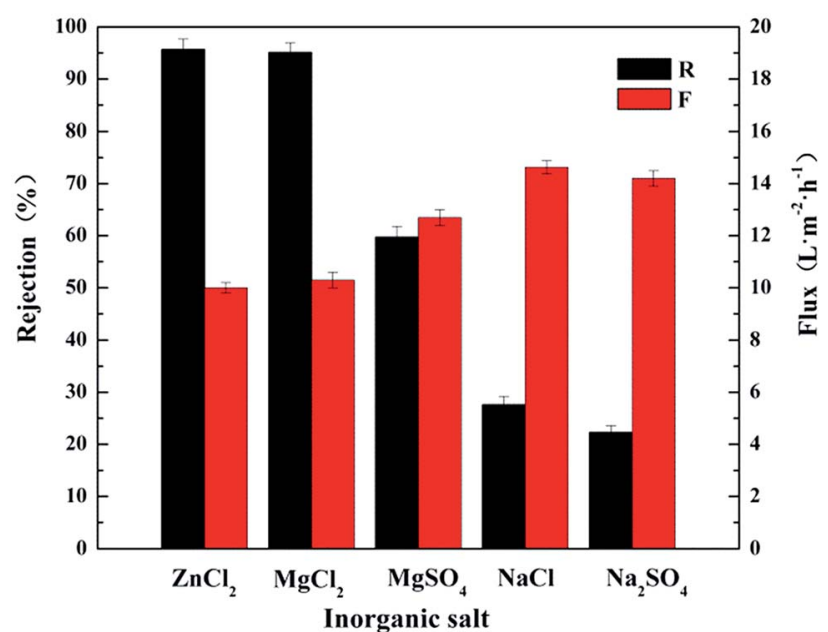

Fig. 5 Rejection performances of CL/PES composite hollow fiber NF membrane to different inorganic salt solutions.
3.4.2. Effects of preparation conditions on the rejection performances of CL/PES composite hollow-fiber NF membranes. Using the CL aqueous solutions with different concentration ranging from 0.1 to $0.3 \mathrm{wt} \%$, the CL/PES composite hollow fiber NF membranes were fabricated under the following conditions: immersion time in the CL aqueous solution: $5 \mathrm{~min}$, interfacial polymerization (IP) time: $120 \mathrm{~s}$, TMC concentration: $0.25 \mathrm{wt} \%$, and curing temperature: $90{ }^{\circ} \mathrm{C}$. The rejection performances of the resultant CL/PES composite NF membranes were investigated, and the results were shown in Fig. 6. As seen from Fig. 6, with increasing CL concentration, the rejection $(R)$ to $\mathrm{MgCl}_{2}$ solution increased gradually from 77.6 to 95.1\%, and the permeate flux $(F)$ decreased from 15.2 to $9.1 \mathrm{~L}$ $\mathrm{m}^{-2} \mathrm{~h}^{-1}$. This might be due to the formation of a more compact and thicker polyamide layer on top of the PES UF membrane with the increase in CL concentration. ${ }^{35}$

The influence of TMC concentration on rejection performance was investigated as well, as shown in Fig. 7. As TMC concentration ranged from 0.1 to $0.35 \mathrm{wt} \%$, the other preparation parameters were as the following: immersion time in $3.2 \mathrm{wt} \% \mathrm{CL}$ aqueous solution: $5 \mathrm{~min}$, IP time: $120 \mathrm{~s}$, and curing temperature: $90{ }^{\circ} \mathrm{C}$. It could be seen from Fig. 7 that the rejection $(R)$ to $\mathrm{MgCl}_{2}$ solution increase from 69.5 to $95.1 \%$ with increasing TMC concentration from 0.1 to $0.25 \mathrm{wt} \%$. The rejection $(R)$ began to decrease as TMC concentration was higher than $0.25 \mathrm{wt} \%$. This could be attributed to carboxylate radical $\left(-\mathrm{COO}^{-}\right)$produced from the hydrolyzation of the excess acyl chloride groups, weakening the positive chargeability of the CL/PES composite NF membrane. ${ }^{36}$ As shown in Fig. 8, the isoelectric point (IEP) of the hollow fiber NF membrane prepared at TMC concentration of $0.25 \mathrm{wt} \%$ was at a $\mathrm{pH}$ value of approximately 9.2. It indicated that the fabricated composite hollow fiber NF membrane is positively charged. And the NF membranes prepared at TMC concentration of $0.30 \mathrm{wt} \%$ and $0.35 \mathrm{wt} \%$ showed the lower IEPs of approximately 8.7 and 8.3. The permeate flux $(F)$ decreased slightly as TMC concentration increased from 0.1 to $0.35 \mathrm{wt} \%$. The reason might be that the

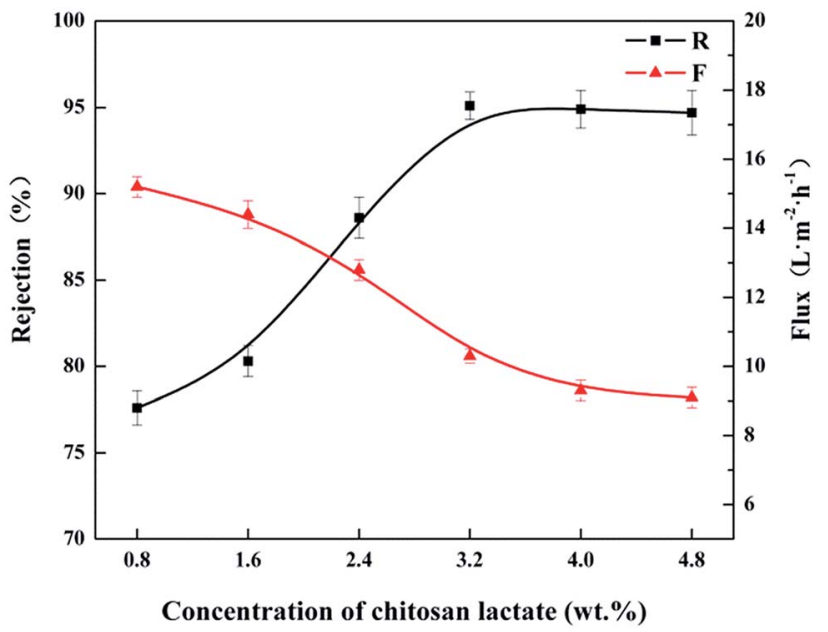

Fig. 6 Effect of $C L$ concentrations on rejection performances of the $\mathrm{CL} / \mathrm{PES}$ composite hollow fiber NF membranes. 


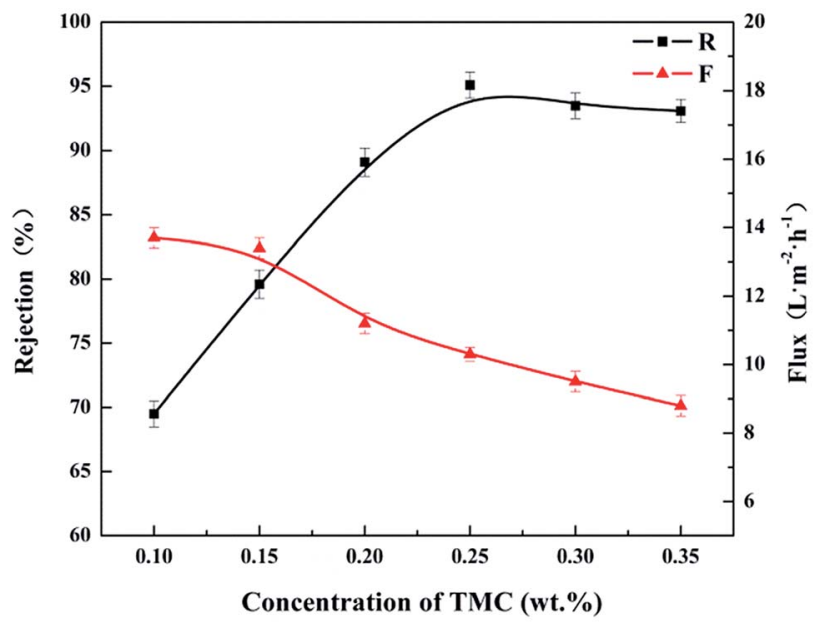

Fig. 7 Influence of TMC concentrations on rejection performance of the CL/PES composite hollow fiber NF membrane.

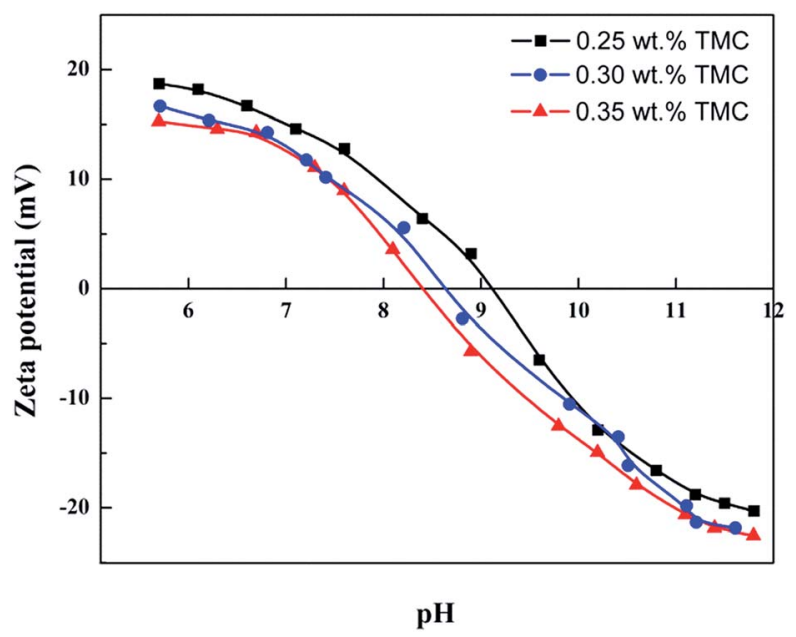

Fig. 8 Zeta potential of the NF hollow fiber membranes (TMC concentration: $0.25 w t \%, 0.30 w t \%$ and $0.35 w t \%)$.

more TMC monomer would accelerate the formation rate of the polyamide layer on top of the PES UF membrane.

The interfacial polymerization (IP) time is an important preparation condition affecting the rejection performance of the resultant CL/PES composite hollow fiber NF membrane. Fig. 9 shows the effects of IP time in the range of 30 to $180 \mathrm{~s}$ on the rejection performances under the condition of immersion time in $3.2 \mathrm{wt} \%$ CL aqueous solution for $5 \mathrm{~min}$, TMC concentration of $0.25 \mathrm{wt} \%$ and heat treatment for $20 \mathrm{~min}$ under $90{ }^{\circ} \mathrm{C}$. The permeate flux $(F)$ decreased sharply with increasing the IP time from 30 to $120 \mathrm{~s}$. As the IP time was prolonged further, there was no significant change in permeate flux $(F)$. It could be explained that the further IP time tend to form a denser active layer, and the IP almost finished in $120 \mathrm{~s}$. The rejection $(R)$ to $\mathrm{MgCl}_{2}$ solution increased firstly, and then decreased with increasing the IP time. The rejection $(R)$ reached the maximum of $95.1 \%$ for $\mathrm{MgCl}_{2}$ solution as the IP time was $120 \mathrm{~s}$. It was due

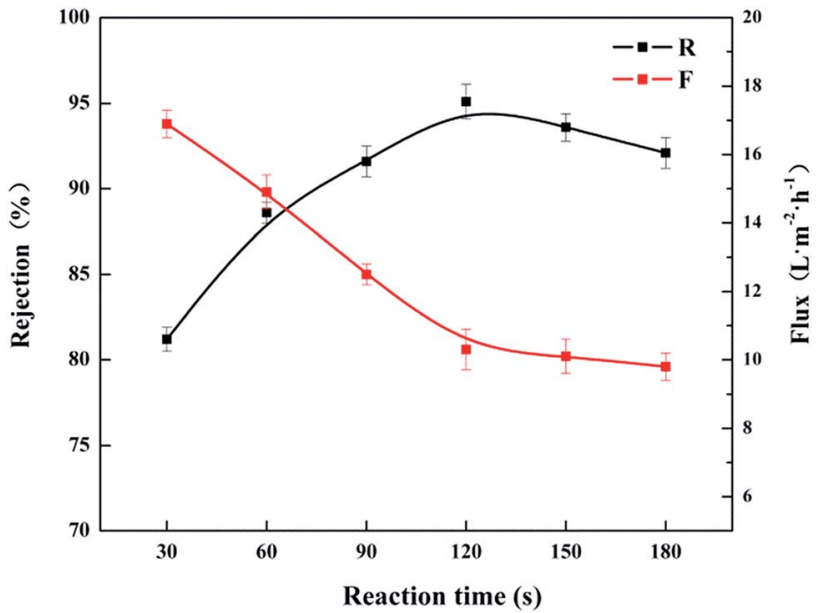

Fig. 9 Effect of IP time on the rejection performances of the resultant $\mathrm{CL} / \mathrm{PES}$ composite hollow fiber NF membrane.

to the unreacted acyl chloride groups as well, which is the same as the effect of excess TMC concentration.

Post-heat treatment is another important way to increase the rejection of the resultant NF membrane. It plays a role in promoting the removal of excess organic solvent from polyamide thin film and facilitating the cross-linking of amine and acyl chloride. Hence the effects of different post-heat curing temperature from 30 to $150{ }^{\circ} \mathrm{C}$ were investigated under the condition of immersion time in $3.2 \mathrm{wt} \% \mathrm{CL}$ aqueous solution for $5 \mathrm{~min}$, TMC concentration of $0.25 \mathrm{wt} \%$, the reaction time for $4 \mathrm{~min}$ and heat treatment time for $20 \mathrm{~min}$. As shown in Fig. 10, the permeate flux $(F)$ of the resultant NF membrane decreased as the curing temperature increased simultaneously. The rejection $(R)$ to $\mathrm{MgCl}_{2}$ solution increased with the increase in the curing temperature, and then decreased as the curing temperature was higher than $90{ }^{\circ} \mathrm{C}$. Since the higher curing temperature would increase the cross-linking degree and accelerate the movements of polymer molecular chains, and the

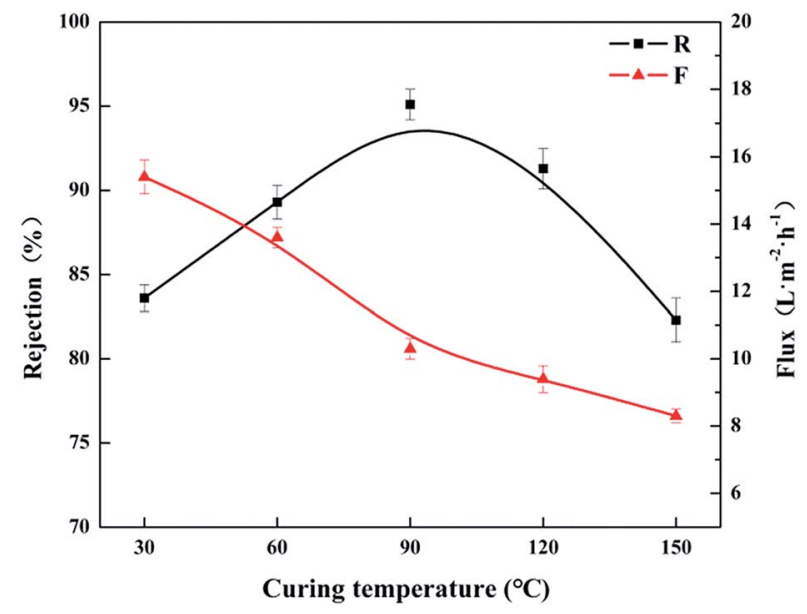

Fig. 10 Effects of the post-heat curing temperature on the rejection performances of the resultant CL/PES composite hollow fiber NF membrane. 
post-heat curing would lead to the shrinkage as well, and then a tighter polyamide active layer was formed. As shown in Fig. S2, $\dagger$ the MWCO of the NF membrane prepared under $30^{\circ} \mathrm{C}$ was approximate $893 \mathrm{Da}$, and the NF membrane prepared under $60{ }^{\circ} \mathrm{C}$ shows the MWCO of $726 \mathrm{Da}$. Moreover, as the curing temperature was higher than $90^{\circ} \mathrm{C}$, the base membrane shrunk further and stripped from the polyamide active layer during the curing period, causing the defects on the membrane surface, and resulting in a decrease in the rejection $(R) .^{36}$ The morphology of the NF membrane prepared under the curing temperature of $150{ }^{\circ} \mathrm{C}$ was characterized with SEM. It could be observed in Fig. $\mathrm{S} 3, \dagger$ the active layer stripped from the base membrane obviously.

3.4.3. Effects of the operating conditions on the rejection performances. The effects of the operating conditions including the operating pressure and the concentration of the feed solution were investigated. Fig. 11 shows the influences of the operating pressure. It could be seen that the permeate flux $(F)$ increased linearly from 5.0 to $25.1 \mathrm{~L} \mathrm{~m}^{-2} \mathrm{~h}^{-1}$ with the increase of the operating pressure from 0.2 to 1.0 MPa. Meanwhile, there was nearly no change in the rejections $(R)$ to $\mathrm{MgCl}_{2}$ solution.

Fig. 12 shows the effects of the feed concentration on the rejection performances at $0.4 \mathrm{MPa}$ and ambient temperature. As the concentration of $\mathrm{MgCl}_{2}$ increased from 0.5 to $2.5 \mathrm{~g} \mathrm{~L}^{-1}$, both of the permeate flux $(F)$ and the rejection $(R)$ to $\mathrm{MgCl}_{2}$ solution decreased gradually. It could be explained by Donnan equilibrium theory. ${ }^{37}$ With the increase in the feed concentration, the electrostatic shielding effect of $\mathrm{Cl}^{-}$ions towards the positively charged membrane increased, resulting in the decrease of membrane charge density. On the other hand, the increase in the feed concentration would lead to a higher osmotic pressure, which decreased the driving force for the permeation and caused the decrease in the permeate flux $(F)$.

3.4.4. MWCO of the CL/PES composite hollow fiber NF membrane. Under the following preparation condition: the $\mathrm{CL} /$ PES composite hollow fiber NF membranes were fabricated under the following conditions: immersion time in $3.2 \mathrm{wt} \% \mathrm{CL}$

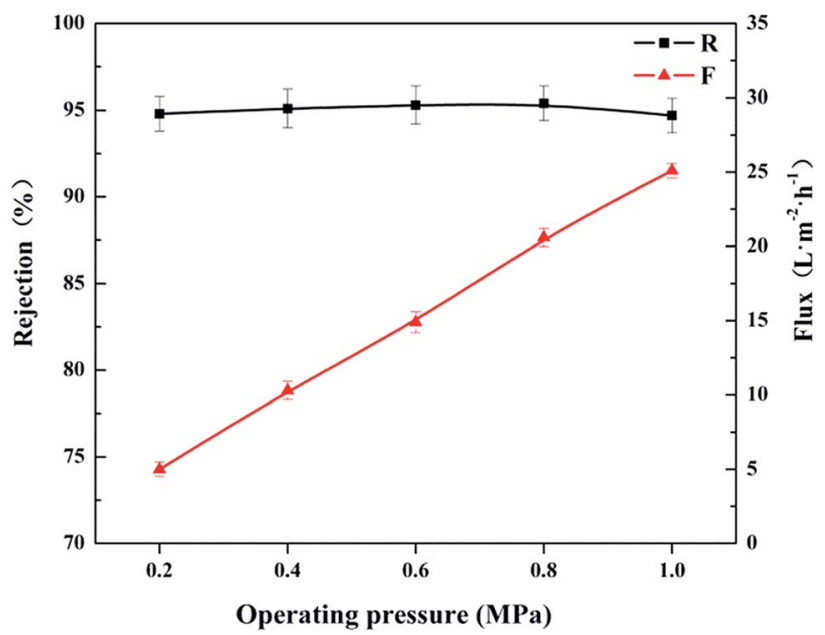

Fig. 11 Effects of the operating pressure on the rejection performances of the resultant CL/PES composite hollow fiber NF membrane.

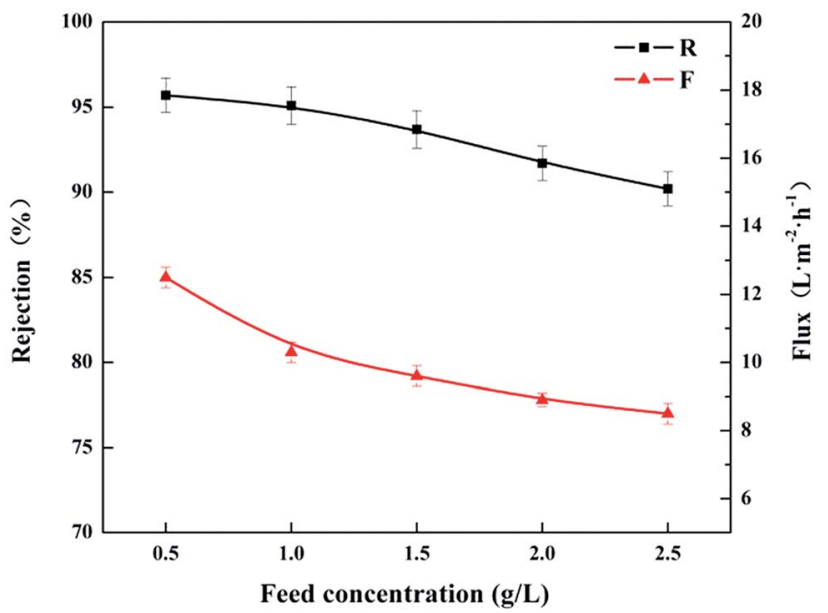

Fig. 12 Effect of the feed concentration on the rejection performances of the resultant CL/PES composite hollow fiber NF membrane.

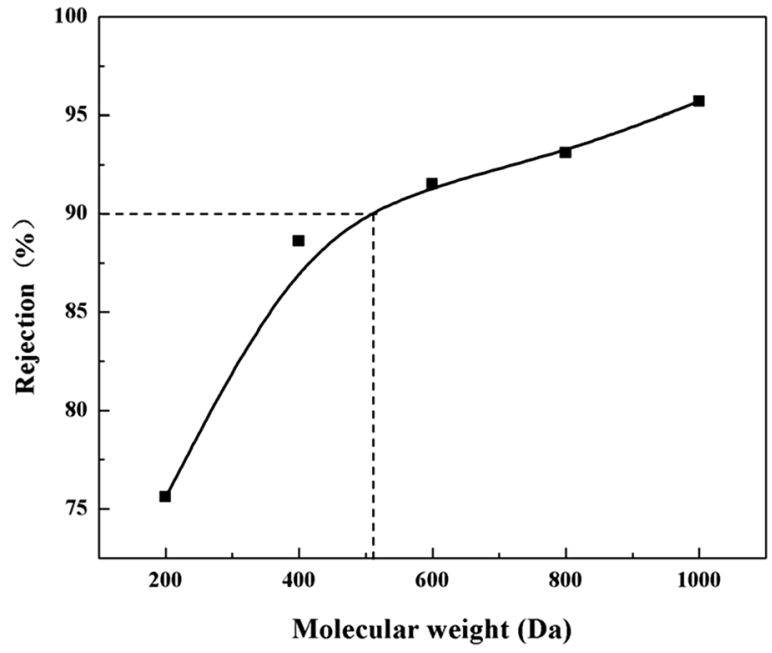

Fig. 13 Rejections of the CL/PES composite hollow fiber NF membrane to PEG with different molecular weights.

aqueous solution: $5 \mathrm{~min}$, interfacial polymerization (IP) time: $120 \mathrm{~s}$, TMC concentration: $0.25 \mathrm{wt} \%$, and curing temperature: $90{ }^{\circ} \mathrm{C}$. The MWCO was determined via the permeation tests using PEG model solutes. The MWCO was determined with the $M_{\mathrm{w}}$ of the PEG when the rejection $(R)$ to the PEG solution is equal to $90 \%$. The rejection $(R)$ to PEG with the $M_{\mathrm{w}}$ ranging from 200 to 1000 Da were shown in Fig. 13. It could be seen that the MWCO of the CL/PES composite hollow fiber NF membrane was approximate $506 \mathrm{Da}$.

\section{Conclusions}

Chitosan lactate (CL) was used as the monomer of the aqueous phase for the interfacial polymerization (IP) on the PES hollow fiber UF membrane for the first time. CL also has the merit of low cost, nontoxicity, and environment friendliness. Compared with the previous researches on chitosan-based NF membranes, 
the aqueous monomer in this work has excellent water solubility and positively charge. In addition, interfacial polymerization has the advantages over coating and cross-linking, such as high reaction rate, short preparation time, and easy operation, which make the industrialization of this work possible in the near future.

The as-prepared CL/PES composite hollow fiber NF membranes were positively charged and following the rejection order to different inorganic salt solutions: $\mathrm{ZnCl}_{2}(95.7 \%)>$ $\mathrm{MgCl}_{2}(95.1 \%)>\mathrm{MgSO}_{4}(59.7 \%)>\mathrm{NaCl}(27.6 \%)>\mathrm{Na}_{2} \mathrm{SO}_{4}$ $(22.3 \%)$. The rejection $(R)$ to $\mathrm{MgCl}_{2}$ solution was $95.1 \%$ while the permeate flux $(F)$ was $10.3 \mathrm{~L} \mathrm{~m}^{-2} \mathrm{~h}^{-1}$ at $0.4 \mathrm{MPa}$ and ambient temperature. It could be known from the cross-section SEM image that the thickness of the polyamide active layer was about $273 \mathrm{~nm}$. The operating pressure and the feed solution could influence the rejection performances of the CL/PES composite hollow fiber NF membranes. This work will provide the base for the positively charged composite hollow fiber NF membranes using the chitosan derivatives as the aqueous monomers for the interfacial polymerizations. There should be the high potentiality for the industrialization of this kind of novel composite NF membrane materials due to the short IP time, the abundance, and the environment friendliness of the aqueous monomers.

\section{Conflicts of interest}

There are no conflicts to declare.

\section{Acknowledgements}

The authors are thankful for the financial support received from the Project on the Integration of Industry, Education and Research of Guangdong Province (2016B090918048), National Natural Science Foundation of China (Grant 21201135), Guangzhou Science and Technology Plan (201604010070), the International Science \& Technology Cooperation Program of Nansha Free Trade Zone (2015GJ002).

\section{Notes and references}

1 S. K. Lim, K. Goh, T.-H. Bae and R. Wang, Polymer-based membranes for solvent-resistant nanofiltration: a review, Chin. J. Chem. Eng., 2017, 25, 1653-1675.

2 A. W. Mohammad, Y. H. Teow, W. L. Ang, Y. T. Chung, D. L. Oatley-Radcliffe and N. Hilal, Nanofiltration membranes review: recent advances and future prospects, Desalination, 2015, 356, 226-254.

3 O. Agboola, J. Maree and R. Mbaya, Characterization and performance of nanofiltration membranes, Environ. Chem. Lett., 2014, 12, 241-255.

4 C. Zhao, G. Hu, D. Hou, L. Yu, Y. Zhao, J. Wang, A. Cao and Y. Zhai, Study on the effects of cations and anions on the removal of perfluorooctane sulphonate by nanofiltration membrane, Sep. Purif. Technol., 2018, 202, 385-396.

5 S. S. Wadekar and R. D. Vidic, Comparison of ceramic and polymeric nanofiltration membranes for treatment of abandoned coal mine drainage, Desalination, 2018, 440, 135-145.

6 J. Liu, J. Yuan, Z. Ji, B. Wang, Y. Hao and X. Guo, Concentrating brine from seawater desalination process by nanofiltration-electrodialysis integrated membrane technology, Desalination, 2016, 390, 53-61.

7 P. Juholin, M. L. Kaariainen, M. Riihimaki, R. Sliz, J. L. Aguirre, M. Pirila, T. Fabritius, D. Cameron and R. L. Keiski, Comparison of ALD coated nanofiltration membranes to unmodified commercial membranes in mine wastewater treatment, Sep. Purif. Technol., 2018, 192, 69-77.

8 R. Shang, A. Goulas, C. Y. Tang, X. d. F. Serra and L. C. Rietveld, Atmospheric pressure atomic layer deposition for tight ceramic nanofiltration membranes: synthesis and application in water purification, J. Membr. Sci., 2017, 528, 163-170.

9 Y. C. Woo, J. J. Lee, W. G. Shim, H. K. Shon, L. D. Tijing, M. Yao and H. S. Kim, Effect of powdered activated carbon on integrated submerged membrane bioreactornanofiltration process for wastewater reclamation, Bioresour. Technol., 2016, 210, 18-25.

10 G. D. Arend, W. T. Adorno, K. Rezzadori, M. Di Luccio, V. C. Chaves, F. H. Reginatto and J. C. Cunha Petrus, Concentration of phenolic compounds from strawberry (Fragaria $X$ ananassa Duch) juice by nanofiltration membrane, J. Food Eng., 2017, 201, 36-41.

11 H. Zhang, Z. Xu, H. Ding and Y. Tang, Positively charged capillary nanofiltration membrane with high rejection for $\mathrm{Mg}^{2+}$ and $\mathrm{Ca}^{2+}$ and good separation for $\mathrm{Mg}^{2+}$ and $\mathrm{Li}^{+}$, Desalination, 2017, 420, 158-166.

12 L. H. Kim and T. H. Chong, Physiological responses of salinity-stressed vibrio sp and the effect on the biofilm formation on a nanofiltration membrane, Environ. Sci. Technol., 2017, 51, 1249-1258.

13 D. L. Oatley-Radcliffe, M. Walters, T. J. Ainscough, P. M. Williams, A. W. Mohammad and N. Hilal, Nanofiltration membranes and processes: a review of research trends over the past decade, Journal of Water Process Engineering, 2017, 19, 164-171.

14 S. Hermans, H. Marien, C. Van Goethem and I. F. J. Vankelecom, Recent developments in thin film (nano)composite membranes for solvent resistant nanofiltration, Curr. Opin. Chem. Eng., 2015, 8, 45-54.

15 F. Zhao, Y. Mi, Q. An and C. Gao, Preparation and applications of positively charged polyethyleneimine nanofiltration membrane, Progress in Chemistry, 2016, 28, 541-551.

16 Z. Liu, J. Cao, C. Li and H. Meng, A review on cleaning of nanofiltration and reverse osmosis membranes used for water treatment, Desalin. Water Treat., 2017, 87, 27-67.

17 J. Gao, S. P. Sun, W. P. Zhu and T. S. Chung, Polyethyleneimine (PEI) cross-linked P84 nanofiltration (NF) hollow fiber membranes for $\mathrm{Pb}^{2+}$ removal, J. Membr. Sci., 2014, 452, 300-310.

18 S. P. Sun, T. A. Hatton and T. S. Chung, Hyperbranched polyethyleneimine induced cross-linking of polyamide- 
imide nanofiltration hollow fiber membranes for effective removal of ciprofloxacin, Environ. Sci. Technol., 2011, 45, 4003-4009.

19 X. Wei, J. Hong, S. Zhu, J. Chen and B. Lv, Structureperformance study of polyamide composite nanofiltration membranes prepared with polyethyleneimine, J. Mater. Sci., 2017, 52, 11701-11714.

20 R. Mahendran and P. K. Bhattacharya, Preparation and characterization of positively charged polysulfone nanofiltration membranes, J. Polym. Eng., 2013, 33, 369-376.

21 Y. Cui, Z. Yao, K. Zheng, S. Du, B. Zhu, L. Zhu and C. Du, Positively-charged nanofiltration membrane formed by quaternization and cross-linking of blend PVC/P(DMA-coMMA) precursors, J. Membr. Sci., 2015, 492, 187-196.

22 T. Mu, G. Tan, G. Du, L. He, Z. Li and X. Li, Novel charged chitosan composite nanofiltration membranes containing chiral mesogenic group, Polym. Eng. Sci., 2017, 57, 22-30.

23 A. Dastbaz, J. Karimi-Sabet, H. Ahadi and Y. Amini, Preparation and characterization of novel modified PVDFHFP/GO/ODS composite hollow fiber membrane for Caspian Sea water desalination, Desalination, 2017, 424, 62-73.

24 L. Garcia-Fernandez, M. C. Garcia-Payo and M. Khayet, Mechanism of formation of hollow fiber membranes for membrane distillation: 1 . Inner coagulation power effect on morphological characteristics, J. Membr. Sci., 2017, 542, 456-468.

25 C. Z. Liang, W. F. Yong and T.-S. Chung, High-performance composite hollow fiber membrane for flue gas and air separations, J. Membr. Sci., 2017, 541, 367-377.

26 E. Liu, X. Xu, X. Zheng, F. Zhang, E. Liu and C. Li, An ion imprinted macroporous chitosan membrane for efficiently selective adsorption of dysprosium, Sep. Purif. Technol., 2017, 189, 288-295.

27 L. Li, J. Zhang, Y. Li and C. Yang, Removal of Cr(vi) with a spiral wound chitosan nanofiber membrane module via dead-end filtration, J. Membr. Sci., 2017, 544, 333-341.

28 M. Gierszewska and J. Ostrowska-Czubenko, Chitosan-based membranes with different ionic crosslinking density for pharmaceutical and industrial applications, Carbohydr. Polym., 2016, 153, 501-511.

29 Y. Tang, L. Wang, Z. Xu and H. Zhang, Novel chitosanpiperazine composite nanofiltration membranes for the desalination of brackish water and seawater, J. Polym. Res., 2018, 25, 118.

30 A. Ghaee, M. Shariaty-Niassar, J. Barzin, T. Matsuura and A. F. Ismail, Preparation of chitosan/cellulose acetate composite nanofiltration membrane for wastewater treatment, Desalin. Water Treat., 2016, 57, 14453-14460.

31 S. Zhuang, Y. Yin and J. Wang, Removal of cobalt ions from aqueous solution using chitosan grafted with maleic acid by gamma radiation, Nucl. Eng. Technol., 2018, 50, 211-215.

32 Y. Zhang, Q. Dang, C. Liu, J. Yan, D. Cha, S. Liang, X. Li and B. Fan, Synthesis, characterization, and evaluation of poly(aminoethyl) modified chitosan and its hydrogel used as antibacterial wound dressing, Int. J. Biol. Macromol., 2017, 102, 457-467.

33 G. S. Shaw, P. M. Pandey, Y. Yogalakshmi, I. Banerjee, S. M. Al-Zahrani, A. Anis and K. Pal, Synthesis and assessment of novel gelatin-chitosan lactate cohydrogels for controlled delivery and tissue engineering applications, Polym.-Plast. Technol. Eng., 2017, 56, 1457-1467.

34 D. Kowalczyk, M. Kordowska-Wiater, J. Nowak and B. Baraniak, Characterization of films based on chitosan lactate and its blends with oxidized starch and gelatin, Int. J. Biol. Macromol., 2015, 77, 350-359.

35 X. Li, C. Zhang, S. Zhang, J. Li, B. He and Z. Cui, Preparation and characterization of positively charged polyamide composite nanofiltration hollow fiber membrane for lithium and magnesium separation, Desalination, 2015, 369, 26-36.

36 R. Han, Formation and characterization of (melamine-TMC) based thin film composite NF membranes for improved thermal and chlorine resistances, J. Membr. Sci., 2013, 425, 176-181.

37 Q. Nan, P. Li and B. Cao, Fabrication of positively charged nanofiltration membrane via the layer-by-layer assembly of graphene oxide and polyethylenimine for desalination, Appl. Surf. Sci., 2016, 387, 521-528. 